\title{
Qualitative differences in academics' conceptions of e-assessment
}

\author{
Mike Mimirinis $^{1}$
}

\begin{abstract}
The paper reports the results of a phenomenographic study on academics' conceptions of e-assessment. A cohort of twenty-one academics from seventeen disciplines participated in semi-structured interviews exploring their experiences of using web-based technologies for formative and summative assessment purposes. Through iterative analysis of the interview transcripts, the study identified four qualitatively different ways in which academic teachers understand e-assessment; e-assessment was seen as a means of: (a) efficiently managing and streamlining the assessment process (b) facilitating dialogue and student engagement (c) enhancing student learning, and (d) developing (digital) identity and the community. Six interrelated dimensions of variation were also established: the benefit of e-assessment, the role of the assessing teacher, the role of the assessed student, the role of the medium, the purpose, quality and level of collaboration, and, finally, the relationship between eassessment and teaching and learning. The results thematise how university teachers relate to technologyenabled assessment and represent incrementally expanding levels of agency within relatively recent, often hybrid assessment milieus. More importantly, the reported dimensions of variation can be utilised to inform which aspects of e-assessment warrant further attention for the improvement of formative and summative assessment design and practice.
\end{abstract}

Keywords: e-assessment $\bullet$ formative assessment $\bullet$ summative assessment $\bullet$ phenomenography • conceptions

\footnotetext{
${ }^{1}$ Mike Mimirinis

Mike.Mimirinis@,anglia.ac.uk
}

Faculty of Health, Social Care and Education, Young Street campus, Anglia Ruskin University, Cambridge, CB1 1PT, UK

https://orcid.org/0000-0003-1835-9348 


\section{Introduction}

The importance of assessment for student learning has been established over decades of scholarly work in higher education (Snyder 1971; Ramsden 1994; Gibbs and Simpson 2004), yet there is much evidence of dissatisfaction with many aspects of the assessment process as evidenced in large-scale evaluation exercises of student experiences (e.g. Higher Education Funding Council for England 2017). Growing emphasis on the assessment of students' work has been attributed to a range of factors such as transparency, accountability (Tremblay, Lalancette and Roseveare 2012), and the need to justify value for higher education provision, all against the backdrop of a continuous shift to marketised provision (Brown and Carasso 2013). Parallel to these developments, research on university teaching and learning has reconceptualised the position, role and importance of assessment and feedback in relation to university students' learning. In particular, this has been reflected in the prioritisation of the alignment of assessment with learning outcomes and teaching activities (Biggs and Tang 2007), the shift of emphasis from assessment of learning to assessment for learning (Black et al. 2007), and systematic approaches to understanding and modelling feedback (Nicol and Macfarlane-Dick 2006). Gipps (1999) notes that many of the innovations in the design and implementation of assessment mark a departure from traditional standardized tests or examinations, instead moving towards a broader notion of assessment for learning, enhancement of learning for the individual, engagement with the student during assessment, and the involvement of teachers in the assessment process. The purpose of assessment, therefore, not only serves the purposes of selection or certification, rather it involves participants' own perspectives in reconstructing their experiences as they learn and undertake assessments.

Looking in the opposite direction, higher education institutions have pressed for a more standardized assessment process, with technology often regarded as a key instrument in implementing such an approach (Vergés Bausili 2017). The massification of the student population on a global scale has led to the need to identify better ways of managing the student work that needs to be assessed. Moreover, the increased ability to reuse material that is available online and the emergence of 'contract-cheating' has forced institutions to adopt plagiarism detection strategies and establish mechanisms for ensuring the authenticity of assessed work. This institutional drive for standardization, however, conflicts with the plurality of new technologies and the multiplicity of options offered to teachers and students to participate in their assessments. These technologies often present decentralised, fringe platforms which may sit well outside the domain where institutionalised learning and assessment take place. Teachers make active choices in utilising these platforms and media depending on whether they believe they serve learning and assessment purposes or if particular features of these e-assessment platforms enhance student engagement and the quality of assessment feedback.

The term e-assessment is defined in this study as the use of web-based technologies for the purposes of formative and summative assessment in the context of university-level formal learning. This term refers to the entire cycle of the assessment process, from designing assessment tasks to the storage and management of the assessment products. Formative e-assessment concerns the use of technology to support the iterative process of analysing information regarding student learning and its evaluation in relation to previous attainment of learning outcomes (Pachler et al. 2010), while summative e-assessment offers evidence of students' achievement, what they know, understand and can do, by assigning a value to their demonstrable achievements. Wiliam and Black (1996, p. 544) remark that 'all assessments can be summative..., but only some have the additional capability 
of serving formative functions', before they continue to emphasise the importance of the concepts of validity and reliability of assessment. Such emphasis is useful in light of the advent of new e-assessment platforms. In particular, concerns have been raised whether e-assessment compromises the validity of the assessment process by allowing for measurement of unintended features (e.g. IT skills, familiarity with, or access to, technology); if that happens, these new technologies insert in the assessment process elements of what is referred to as 'construct-irrelevant variance' (Wiliam and Black 1996, p. 539).

Moreover, a distinct stream of work on face-to-face formative assessment and assessment for learning has shifted the focus of attention to how feedback helps students recognising their next steps in their learning and what they can actually do with the information they receive (Ramaprasad 1983; Hattie and Timberley 2007; William 2011; Boud and Molloy 2013). Gikandi, Morrow and Davis (2011) pointedly note, however, that formative $e$-assessment includes characteristics that differ from face-to-face contexts, amongst other factors, due to the often asynchronous nature of the participants' interactivity in online instructional settings. Limited work has been undertaken to transfer and apply the scholar work on assessment for learning and formative assessment into the online context. Such work is even more rare, when the role of the e-assessing teacher is considered. Technological determinism and corporatised views of university functions, often overlook the role of the teacher in the e-assessment process including their role as a key agent of enacting principles of assessment for learning. When this role is acknowledged, it often places the practitioner within a 'teacher-deficiency' model where the provision of assessment 'techniques' or enrolment on training programmes attempts to address the 'shortcomings'. This approach bypasses some crucial questions, namely what do teachers believe e-assessment is and how do their beliefs and intentions towards e-assessment influence their practice? This is particularly relevant given that the gap between teachers' espoused and enacted theory (Argyris and Schön 1974) is a prominent issue when considering assessment practice (Thomson and Falchikov 1998).

In considering these developments, the current study aims to extend two existing clusters of previous areas of contribution: firstly, empirical studies reporting on academics' conceptions of assessment (exclusive of eassessment) and, secondly, studies exploring conceptions of technology-enhanced learning and instruction without explicitly addressing e-assessment. Influential studies on teachers' conceptions of their own teaching (Prosser, Trigwell and Taylor 1994; Kember 1998) have revealed a continuum of conceptions of, and approaches to, teaching, ranging from teacher-focused/content-oriented to student-focused/learning-oriented (Kember 1997). Entwistle (2000) has noted that limited evidence suggests that contrasting conceptions of teaching tend to reflect corresponding views on assessment: content-oriented teaching more aligned with assessment as designed to demonstrate factual knowledge while, conversely, learning-oriented teaching tend to be aligned with more varied methods of assessment and bearing responsibility for students' learning. Employing a grounded theory categorization method, Samuelowicz and Bain (2002) have explored beliefs about the nature of assessment and identified a range of 'orientations,' from knowledge reproduction to knowledge construction and/or transformation, while suggesting that orientation to assessment is broadly related to orientation to teaching and learning; later studies have reported similar findings (e.g. Postareff et al. 2012). Adopting a phenomenographic approach, Watkins, Dahlin and Ekholm (2005) have reported on conceptions of the backwash effect of summative assessment in samples of academic teachers in Sweden and Hong Kong. They argued that two features of these conceptions are important in terms of changing teachers' views of the role of 
assessment: namely, how the teacher understands the significance of disciplinary 'basic' knowledge and whether teachers reflect on the relationship between teaching and assessment.

While these studies have explored conceptions of assessment, the role of technology has not been explicitly investigated. This has been the focus of a stream of phenomenographic studies exploring variation in the way university teachers' experience technology-enhanced learning, and teaching. These studies reported on academics' conceptions of, and approaches to e-learning, blended learning and teaching design with technologies (Ellis, Steed, and Applebee 2006; Ellis et al. 2009; González 2009, 2010). In one of the key contributions of this cluster of studies, Ellis, Steed and Applebee (2006) have asserted that conceptions of blended learning that focus on the use of technology as a means of achieving learning outcomes are associated with conceptions of blended learning that prioritise students' construction of meaning. Closer to the scope of the current study, González (2010) has thematised teachers' conceptions of e-learning in four descriptive categories: to provide information to students; to facilitate peer-to-peer student communication; to engage students in online discussions; and to support knowledge-building activities.

In summary, it has been established that how university teachers understand teaching- 'conceptions of teaching'- is intimately linked to their approach to teaching which in turn influences their students' approaches to learning and the quality of their learning outcomes. Recent phenomenographic studies extended this research in the area of online teaching and learning, and identified variation in the ways academic teachers understand the role of technology in their teaching. It is not known, however, how/whether conceptions of $e$-assessment relate to this work and what associations might exist between conceptions of e-assessment and aspects of the teaching and learning environment. This gap has not been covered by the limited number of previous studies on conceptions of assessment where the role of technology has not been accounted for, even though these studies offered a useful framework of orientations to assessment ranging from 'knowledge reproduction' to 'knowledge construction/transformation'. Building on the premise that changes in academics' conceptions are essential to enact changes in practice, the present study intends to address this gap and is particularly relevant in the backdrop of increasingly interpretivist approaches to assessment, the hybridisation of assessment formats brought about by successive waves of technological advances and the growing concerns about issues of students' academic integrity and authenticity of their work. The research question of the study was therefore formulated as: what are the qualitatively different ways in which academics in higher education experience and understand e-assessment?

\section{Methodology}

The phenomenographic approach attempts to describe e-assessment from a second order perspective (Marton and Booth 1997), namely from the perspective of academics involved in e-assessing student work in face-toface, blended and online environments. This research approach therefore studies e-assessors' interpretations of the given phenomenon. The benefit of adopting a phenomenographic approach is two-fold: utilise the 'powerful heuristic value' of the approach (Åkerlind and Kayrooz 2003, p.340) in the context of exploring a previously under-researched area and, secondly, capture the collective meaning in the experiences of academic teachers beyond individual differences of the experience of e-assessing. Whilst a phenomenography approach allows to represent the structure of the collective meaning, it can be difficult to maintain the nuances of the context that 
this structure emerges from. It is equally difficult to associate characteristics of the sample with particular conceptions, hence limiting the interpretive breadth of this approach. Twenty-one teachers with frequent eassessment responsibilities were invited to attend semi-structured interviews with the author. The sample was drawn from a modern British higher education institution at the end of a university-wide initiative concerned with implementing e-assessment across all levels of undergraduate study. A number of disciplinary backgrounds (Figure 1) and varying levels of e-assessment experience was sought at the stage of selecting participants for interviews.

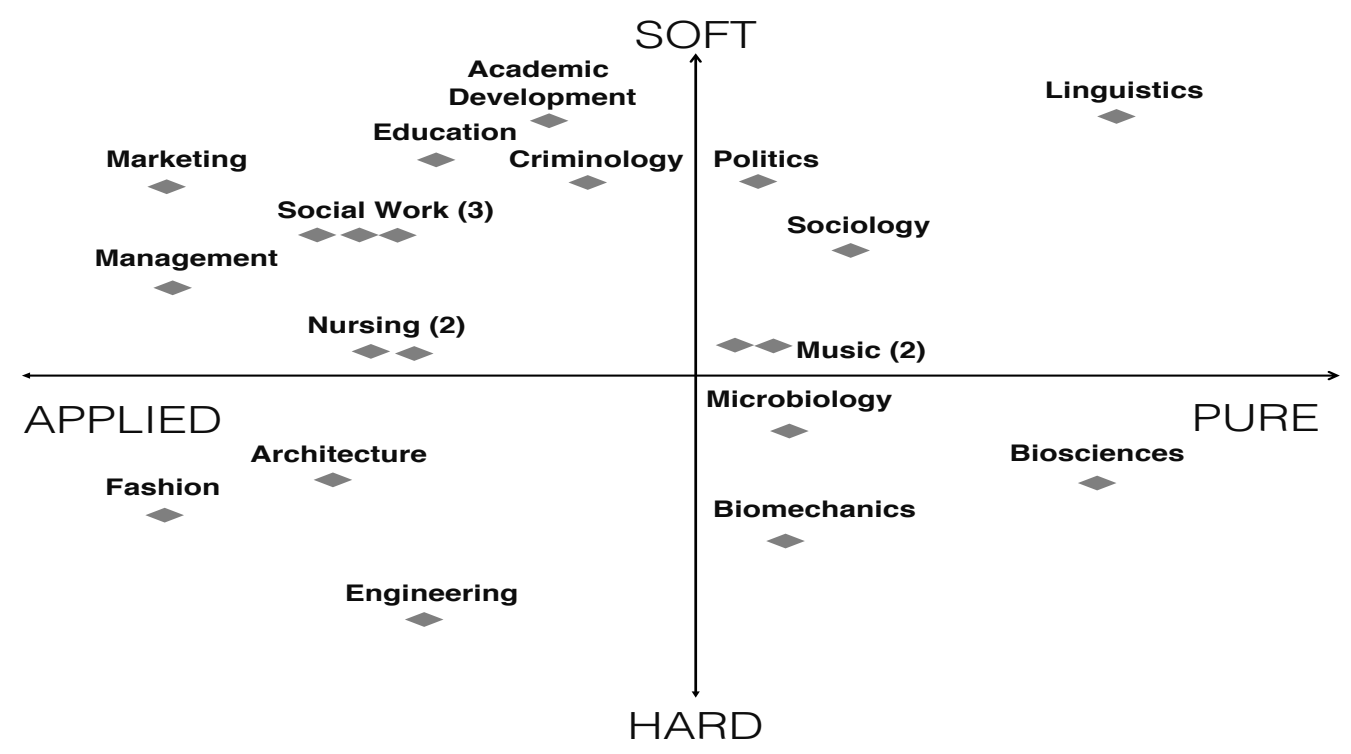

Figure 1: Relative position of study participants' disciplinary/field background on 'applied/pure' and 'hard/soft' axes

(Becher and Trowler 2001). Number in brackets denotes participants from same discipline/field. N=21

These ranged from academics with only months of experience to those with more than thirty years of experience, including experience in computerised assessments which preceded the advent of the world wide web. Participants' disciplinary background, employment status and gender have been disaggregated from Table 1 so that full anonymity is preserved. Thirteen female and eight male academics attended an interview with the author. Eighteen participants were full-time academic staff and three part-time. The author prompted participants to describe their experiences of e-assessment in general, before asking detailed questions about a particular formative or summative e-assessment instance. There was no preference to formative or summativeassessment on the part of the interviewer, neither was there any preference for any particular e-assessment medium/format. On the contrary, interviewees were invited to choose an instance they were keen to describe in detail while the probing questions focused on revealing the structure of the conception. Standard questions in each interview included: 'What does e-assessment mean to you?' and 'What can be achieved with eassessment?' followed by prompting questions such as 'What makes you say that?' or 'Why is that important?'. 
Table 1: Study participants

\begin{tabular}{|c|c|c|c|c|}
\hline Participant & $\begin{array}{l}\text { Academic } \\
\text { Rank }\end{array}$ & $\begin{array}{c}\text { Years of } \\
\text { teaching } \\
\text { experience }\end{array}$ & $\begin{array}{l}\text { Years of e- } \\
\text { assessment } \\
\text { experience }\end{array}$ & $\begin{array}{c}\text { Medium/format for formative or summative e- } \\
\text { assessment }\end{array}$ \\
\hline P01 & Senior Lecturer & 11 & 3 & $\begin{array}{l}\text { Discussion groups, Electronic Management of Assessment } \\
\text { (EMA) with Turnitin, online videos }\end{array}$ \\
\hline $\mathrm{P} 02$ & Professor & $30+$ & $25^{*}$ & $\begin{array}{l}\text { Computer-assisted assessment, EMA with Learning } \\
\text { Management System (LMS), discussion forum }\end{array}$ \\
\hline $\mathrm{P} 03$ & Senior Lecturer & 20 & 10 & EMA with Turnitin, blog \\
\hline P04 & Senior Lecturer & 10 & 1 & EMA with Turnitin, blog \\
\hline P05 & Senior Lecturer & 7 & 4 & $\begin{array}{c}\text { EMA with Turnitin, blog, Visual essays, Instagram, } \\
\text { Whatsapp, Twitter }\end{array}$ \\
\hline P06 & Assoc. Prof. & 13 & 6 & $\begin{array}{l}\text { Online audio and video feedback, EMA with Turnitin, } \\
\text { Mobile app }\end{array}$ \\
\hline P07 & Assoc. Prof. & 26 & 4 & EMA with Turnitin, blog \\
\hline P08 & Assoc. Prof. & 14 & 7 & Web conferencing feedback, Virtual world, Online forum \\
\hline P09 & Senior Lecturer & 8 & 2 & Online Multiple Choice Questions (MCQs), e-portfolios \\
\hline $\mathrm{P} 10$ & Professor & $30+$ & $25^{*}$ & $\begin{array}{l}\text { Computer-assisted assessment, Massive Open Online } \\
\text { Course (MOOC), Quizzes, online journal, blog }\end{array}$ \\
\hline $\mathrm{P} 11$ & Senior Lecturer & 9 & 3 & $\begin{array}{c}\text { EMA with Turnitin rubrics, e-portfolio, diagnostic tests } \\
\text { embedded in e-books }\end{array}$ \\
\hline $\mathrm{P} 12$ & Professor & 15 & 5 & $\begin{array}{c}\text { Digital story-telling, e-portfolios, discussion threads, } \\
\text { Youtube }\end{array}$ \\
\hline P13 & Lecturer & 3 & 1 & EMA with Turnitin, Audio feedback, Online role play \\
\hline P14 & Senior Lecturer & 17 & 3 & EMA Turnitin, MCQs and short answer questions \\
\hline P15 & Assoc. Prof. & 19 & 8 & EMA with Turnitin audio feedback and rubrics \\
\hline $\mathrm{P} 16$ & Assoc. Prof. & 23 & 8 & EMA with LMS \& Turnitin, online formative assignments \\
\hline P17 & Lecturer & 7 & 7 & EMA with LMS rubrics, MCQs \\
\hline $\mathrm{P} 18$ & Lecturer & 2 & 5 & e-portfolio, blog, discussion threads \\
\hline P19 & Lecturer & 11 & 3 & EMA with Turnitin, Twitter \\
\hline $\mathrm{P} 20$ & Senior Lecturer & 15 & 2 & EMA with Turnitin \\
\hline $\mathrm{P} 21$ & Lecturer & 2 & 2 & EMA with Turnitin, MCQs \\
\hline
\end{tabular}

*including experience with computer-assisted assessment

Stimulated recall technique was employed when participants voluntarily expressed the will to demonstrate examples of their experiences. A laptop was available on the desk and participants were informed that this could be used at any point during the interview; four participants asked to use the laptop. The technique was employed with the objective of yielding richer accounts of e-assessment experiences while revealing the structure of 
participant conceptions. Interviews lasted between 30 and 60 minutes and were audiotaped and transcribed by a third party. The analysis of the generated data involved five stages:

During the first stage, the transcripts from each interview were read once while listening to the interview audio files. Transcription completeness and accuracy were confirmed and any mistakes were corrected. The author also recalled the particular nuances of each interview. Subsequent readings of the transcripts served the purpose of marking 'meaningful utterances', potentially revealing aspects of the conceptions' structure. When in doubt about the usefulness of a particular passage, the latter were maintained at this stage of analysis so that they could be re-examined.

The second stage, involved a round of analysis which attempted to ascertain the exact limits of each meaningful utterance. By doing so, the study addressed the issue of how much of each interview transcript should be considered (Åkerlind 2012). The approach reported here made use of the distinction between theme, thematic field and margin (Gurwitsch 1964; Marton and Booth 1997). Aspects of participants' interview accounts not directly related to e-assessment were categorised as belonging to the margin of awareness and were excluded from further analysis. A more focused reading of the transcripts was narrowed down to distinguish which aspects within the thematic field of the phenomenon belong to the fore and become central to a teachers' focus of awareness; these were marked as belonging to the theme of awareness. Once these extracts were delimited, a 'pool of meanings' was constructed and the extracts were separated from the individual transcript (Marton 1986). The third stage entailed an iterative reading of the extracts in the pool of meanings, which searched for similarities and differences between and within relevant sections of the interviews. Illustrative paragraphs were annotated and preliminary descriptions were drafted regarding what the focus of awareness was while eassessing students' work and how they described this; these were assigned temporary, broad labels. During the fourth stage, the extracts in the 'pool of meanings' was read again in relation to the provisional categories of description. The aim of the analysis at this stage was threefold: firstly, to see if the categories accurately represented the experiences described by the teachers as evident in the data; secondly, to ascertain that categories were logically related to each other and inclusive within a hierarchical structure; thirdly, to establish that the label of each category of description convincingly represented teachers' accounts in the interviews. Iterative readings were continued and extracts were moved across categories where it was essential to consolidate the categories of description. Extracts which exemplified variation between the categories and exemplified the differences between categories of description were highlighted. Finally, in the fifth stage, the analysis moved from constructing categories of description to identify the structure of the outcome space. Provisional results and the 'pool of meanings' were then read by two researchers trained in the phenomenographic method who independently checked the findings' validity. In the final stage of the analysis, provisional results were presented to a phenomenographic convention and participants with varying levels of experience in this approach were invited to comment with a view to establishing whether the results resonated with their understanding of the phenomenon and to enhance the communicative validity of the study (Kvale 1996).

\section{Results}


Four categories of description were identified from the analysis of the data. Thereby, e-assessment can be seen as a means of:
a. Efficiently managing and streamlining the assessment process;
b. Facilitating dialogue and student engagement;
c. Enhancing student learning;
d. Developing (digital) identity and the community.

Table 2 provides an overview of the four categories of description. Renström (1988) has noted that the same conceptions may encompass different constituent parts of the phenomenon that can be focused upon. These different foci emerged in the analysis of the transcripts and are reported under each conception as 'core constituent foci'.

Table 2:

\section{Categories of description}

\begin{tabular}{cl} 
Category & Description \\
\hline A & E-assessment as a means of efficiently \\
& managing and streamlining the assessment \\
& process \\
& Core constituent foci: \\
& - enhancing accessibility, transparency and \\
& clarity \\
& - ensuring fairness and consistency \\
& - assigning value to student work and testing \\
& accuracy of acquired knowledge \\
& - tracking, monitoring and plagiarism detection \\
& \\
& \\
& E-assessment as a means of facilitating dialogue \\
& and student engagement \\
& Core constituent foci: \\
& - providing (iterative) feedback \\
& - enhancing clarity, monitoring and \\
& transparency of communication \\
& - establishing teacher presence and encouraging \\
& student participation and attendance \\
& \\
& \\
& E-assessment as a means of enhancing student \\
& learning. \\
& Core constituent foci: \\
& - providing constructive, developmental \\
feedback & - developing ideas and gaining skills \\
& - negotiating assessment \\
& improving course-wide experience \\
& \\
& \\
&
\end{tabular}

\section{Excerpt}

e-assessment is that students can easily submit it, they don't have to leave their home, they don't have to be running to the library or wherever to get it there for the time. It's trackable, so even if it gets deleted there's normally some metadata that you can actually track it. And, of course, in terms of us marking you can be marking anywhere, so you're not restricted to one venue or having to carry piles of dissertations and essays around. [P05]

The key thing here is flexibility and also respecting the diversity of students. I think, you know, you might have a student who is not able to attend the class but still he can take the test online. You might have a student who doesn't feel comfortable presenting himself or he might feel more comfortable when he would have sent you a video. [P21]

We've run that over ten weeks and each week it is marked and they must submit by Sunday evening and they lose marks if they are late, so it keeps them to a time frame and it keeps them working every week on it and, yeah, they engage with it. [P09]

Have a sort of electronic document written to whatever requirements and standard, depending on what the context of the work is and that you can have this sort of exchange, I suppose. The student generates the work and the tutor can look at it and can give initial feedback in an electronic form and the student can work on that piece of work as well. So, it can achieve that you have a more two-way exchange if it's used in the formative and developmental stage of the work. [P11]

Often we just use it as the form of submitting and then the e-part doesn't really have a significant impact on the nature of the assessment but I think with certain types of assessment you can ensure that you can embed learning resources into the assessment. So that the students can use the assessment really as a learning tool and not just as a sort of electronic form of submitting a piece of work. And I think that's when you really have the power of the e-assessment, when you can make it more embedded so that you have your assessment with links to various learning tools. [P11]

I don't see e-assessment as a thing that can be viewed in isolation. E-assessment is something which is tied in with teaching, through online materials, online activities, tutorials with students, so-called chalk and talk sessions with students, workshops, practical activities, extra-curricular activities, the student's own work on their own and in groups [...]. One can't, I feel, isolate e-assessment as a way of teaching and learning. [P16] 
E-assessment as a means of developing (digital) identity and the community

Core constituent foci:

- enabling collaborative work and shared experiences within the (digital) cohort

- harnessing collective wisdom

- co-authoring of assessment

- supporting students' autonomy

- serving university's mission as a public institution

- contributing to successful citizenship and professional life
The very act of creating assessment feedback is a content creation activity. So it produces, as well as producing something of value to the individual students, specific to their particular piece of writing or task, it is producing a rich repository of information which is reflective of the combined wisdom of the academic staff, and at the moment, that's just dumped into a system and it's not viewed, we've not made any attempt to pull that combined wisdom together to extract the essence of that wisdom or feedback to be of benefit to other people. [...] Each student may or may not extract something useful, but there's a wisdom of the crowd, a collective wisdom, that's sitting in that assessment database. [P02]

There are a number of ways of judging if any kind of assessment is successful and eassessment is not different. So, from the teacher's point of view, I think we feel that we want to have as many students as possible achieving well i.e. self-esteem, confidence levels; no doubt, grades are an issue but also for us, because we're in teacher training, getting a job, so successful application for a career. [...] And then I guess in the wider community, e-assessment, you know it's been successful if we have a good reputation, our students get jobs, they stay in their jobs, they contribute as citizens. [...] So there are philosophical ways to look at this in terms of a university's success, engaging with society productively and also having a reputation that other universities and wider culture recognise. [P07]

Category A: e-assessment as a means of efficiently managing and streamlining the assessment process

Category A represents a view of e-assessment as a means of efficiently managing and streamlining the assessment process. Fulfilling the requirements of this process entails accurately matching feedback with learning outcomes and accelerating the pace of administrative functions between all parties (lecturers, students, external moderators, university administrators). Achieving efficiencies means swiftly accessing scripts and providing secure and convenient storage for exam materials. In addition, e-assessment is seen as a means of organising marking: for example, e-assessment tools can be used as an 'aide memoire' [P01] to allow markers to maintain the consistent application of marking criteria and feedback. Enabling access for all parties involved in assessment is a crucial focus of interviewees' awareness in this category. This is perceived as contributing to greater transparency and clarity in terms of who is participating in the marking, what are they doing, and whether their actions and judgements are trackable. Crucially, within this category e-assessment allows for plagiarism detection and reduces the administrative burden associated with documenting sources of plagiarism as it automatically detects the source of the plagiarised material. While this refers to the summative aspect of assessment, formatively monitoring students' progress is also perceived as a benefit: both contribute to verifying the authenticity of submitted work. A core constituent focus within this category sees e-assessment as instrumental to the process of not only verifying authenticity but also that students are 'tested' on whether they received the right amount of knowledge and whether this can be evidenced. Such a process, in turn, is associated with the assignment of a pass or fail value and streamlined into the administration of assessment: release and confirmation of results, managing appeals, awarding credits etc. Finally, e-assessment is seen as accommodating different 'learning styles' [P21] and learning preferences; the focus of awareness is not, however, on learning but on convenience, flexibility, ease of access and choice.

\section{Category B: e-assessment as a means of facilitating dialogue and student engagement}


In this category e-assessment is experienced as a suitable means of enriching the quality and increasing the quantity of communication in the assessment process, most importantly by improving the quality, quantity and timeliness of feedback in assessments intended for either formative or summative purposes. Under this category, online platforms allow for diversification of communication channels and for the teachers' messages to reach wider audiences 'than just one to one' [P01]. The 'conversation' [P01, P05, P07, P15], 'relationship' [P03, P05], 'discussion' [P03, P08] or 'exchange' [P05, P10, P11] centres on accessible, timely ways of communicating the submission and feedback, thereby establishing teacher presence ('so we have to keep our presence known to them', P05). Whereas in Category A academics described transactional, administrative relationships (mostly fulfilling external requirements), in Category B the attention is placed on relationships between teachers and students or - less frequently - between peers. It is not coincidental that peer assessment emerges in the accounts of teachers relevant to this conception of e-assessment.

\section{Category C: e-assessment as a means of enhancing learning}

The focus of this category is on student learning. Peer assessment and peer feedback are seen as important elements of assessment and are clearly linked to the 'enhancement' [P01, P06, P14, P18] of student learning. Feedforward frequently emerges in the accounts of this category of description. Emphasis is placed on the development of ideas and skills [P01]. In turn, e-assessment is seen as a 'multi-directional' [P02] system where learning can occur for all stakeholders partaking in assessment, nevertheless the prime focus remains students' learning. Fragments of understanding of assessment as a negotiable process appear in this category. Online platforms are understood to decisively change the balance between summative and formative assessment, in favour of the latter; iterations of formative feedback are served by various web-based media including sociallyoriented platforms. Alignment of e-assessment with learning outcomes is framed in terms of student learning rather than simply meeting prescribed institutional requirements. The accounts often refer to how inseparable eassessment and teaching/learning are. Assessing 'process' [P12] is incrementally perceived as more important than assessing content. A core constituent focus refers to e-assessment as a curating process [P02, P16] aiming at enhancing student learning. The emphasis is on intentional and systematic curation and design of resources with the explicit ambition to assist students' learning development. The teacher is seen as an assessor as well as a learning facilitator and a creative curator of assessments.

\section{Category D: e-assessment as a means of developing (digital) identity and the community}

Accounts consistent with this category prioritise collaboration as a means of achieving collective aims. The purpose of e-assessment transcends the boundaries of teacher-student or student-student relationships and refers to collective ideas, objectives and spaces. Students are seen as potential partners in the design of e-assessment systems and tasks, capable of co-authoring and controlling them while negotiating the process [P07]. 'Selfgrowth' [P18], autonomy, development of digital identity within digital communities and cohorts are seen as equally important. Individual development is seen in relation to collective, professional or societal contexts. 
Technology can enhance the combination of individuals' contributions to the assessment cycle - particularly feedback - and, therefore, form a repository of 'collective wisdom' [P02].

\section{Dimensions of variation}

Six dimensions of variation were identified through the iterative analysis of the interview transcripts. These describe aspects of e-assessment as experienced by academics that appear across the four categories of description but change within each one of them. The five interrelated dimensions of variation are:
a. The benefit of e-assessment
b. The role of the assessing teacher
c. The role of the assessed student
d. The role of the medium
e. The purpose, quality and level of collaboration
f. The relationship to teaching and learning 
Table 3: Dimensions of variation (overview)

The benefit of eassessment

The role of the assessing teacher

The role of the assessed student

The role of the medium

The Purpose (P), Quality

(Q) and Level (L) of

Collaboration

The relationship to teaching and learning

Q: Transactional

$$
\text { Category A }
$$

\section{Category B}

Access, flexibility, efficiencies, fairness, consistency, transparency, storage

Administrator, manager, plagiarism detector

Recipient of results and feedback, system user

Transactional

P: Supporting administration

L: Low and mostly uni-directional
Clarity, timeliness

of communication and richer engagement

\section{Communicator,} conversation partner

Communicates and participates

Communicative

P: Supporting dialogue

Q: Relational

L: High and multidirectional
Category C

Development of students' ideas and skills

Facilitator of learning

Active learner and partner in the assessment process

$$
\begin{gathered}
\text { Instrumental to } \\
\text { teaching and } \\
\text { learning }
\end{gathered}
$$

P: Supporting learning

Q: Relational

L: High and multi-directional

Internal
Category D

Aggregating collective wisdom, professional development, personal growth, civic benefit

Mentor

Developing as an individual within cohort, online collective spaces and the society

Instrumental to the development of the individual within cohort, community

P: Supporting collective processes

Q: Relational

L: High and multidirectional

\section{The benefit of e-assessment}

This dimension interweaves all categories of description and ranges from describing the benefit of e-assessment in organisational/technological (Category A) to personal/collective development terms (Category D) respectively. It is important to note that the dimension of variation refers to what the perceived benefit is rather than who benefits. Category A clearly reflects the benefit of e-assessment as an issue of increased accessibility and flexibility for all those involved in the assessment of student work. In Category B the benefit is seen in terms of increased communication with students which is clear and timely, enriches feedback and teaching presence, and ultimately is understood to lead to extended student engagement. In Category $\mathrm{C}$ the benefit is articulated in terms of skills attainment and the development of ideas that ultimately enhance student learning while this is extended in Category D to refer to the benefits of e-assessment for professional development, personal growth, and wider societal benefit.

\section{The role of the assessing teacher}

This dimension captures the changing role of the assessing teacher in e-assessment. In Category A, the eassessor is understood to play the role of the efficient administrator who detects plagiarism and ensures the fairness and consistency of the assessment. Moving on to Category B, the role is seen as a communicator and conversation partner. Sophisticated functionalities can underpin such a teacher role. Both Categories C and D 
see the teacher as facilitator; in Category $\mathrm{C}$ the teacher/assessor facilitates learning and skills development and utilises the e-assessment system to guide student learning, whereas in Category D the teacher facilitates personal development and growth through the intentional use of e-assessment system; they, therefore, act more as mentors.

\section{The role of the assessed student}

The role of the student is predominantly viewed using a transactional lens in Category A; the student submits work and receives formative feedback or summative results. The student is also seen as user of the e-assessment platforms. Moving on to Category B, the role becomes more active, involving engaging in a conversation with the teacher or other students. As one interviewee stated: 'the role of the student is very much part of the conversation' [P05]. These elevated levels of engagement and participation are further extended in Category C where the assessed student is seen as an active learner and a partner in the assessment process. A notion of a negotiating or co-authoring partner in the assessment process emerges here: "It's a case of if you make a jacket - Turnitin or e-assessment here - if you make it a straitjacket then it inhibits learning ultimately, and if it's a very loosely formed jacket that can fit anyone and has a nice lot of flexibility and adaptability within it, it becomes something that teachers or students feel they can author, they can have a role in co-authoring" [P07]. These conceptualisations of the role of the student in the e-assessment process are further elaborated in Category D; the student here is active not only in the assessment tasks but also within the online/classroom cohort, collective spaces and professional communities.

\section{The role of the medium}

This dimension reflects the accounts of academics on the role of the e-assessment medium, extending from an understanding of the medium as a transactional mechanism to a more advanced understanding as an instrument for personal and collective development. Within Category A, the medium supports administrative transactions; these take several forms and follow multiple directions between students, teachers, university administrators, eassessment system managers and external moderators, quality assurance and professional accreditation bodies. Within the second category of description, the medium is perceived to enable a communicative function; certain platforms may better serve this purpose; therefore, in the academics' accounts dialogic- and socially-centred media appear more often and play a central role in facilitating the intended communicative functions. These functions become instrumental in supporting student learning and skills development in Category C. The teacher appreciates the medium in relation to how well it supports the achievement of course, module or individual teaching session learning outcomes. Platforms that underpin personal and collective growth appear to be chosen in Category D, while socially-oriented media are described as supportive of these goals alongside media which present the potential to scaffold professional development. Typically, academics' accounts of the less advanced conceptions (A, B), describe the impact of the medium in terms of what it offers to the teacher, with some of the metaphors being illuminating:

'You're hugely busy marking an enormous amount of work. So any assessment and feedback system 
has to be as efficient as possible. So I think, you know, I'm definitely looking for systems that enable that and don't make it more difficult or longer' [P01].

Additionally, the e-assessment platform can be seen as a two-way barrier for assessed students and the assessing teacher, bringing about substantial changes to their perceived role and identity.

I think when the students submit via Turnitin, and they know that I mark it but I think it becomes less clear, that somehow Turnitin does some of the marking as well, it's like a digital marker. So I guess it changes me in a sense, I become sort of artificially intelligent through my kind of engagement with Turnitin, whereas if I'm marking a hard copy then I'm not, I'm just me. So I guess it's me who's experiencing the kind of ontological shift, that I'm becoming more of a kind of... Because I'm not an IT expert, I don't really understand these systems and I think asking the students to engage with the software creates this kind of mediating effect that's not helpful. So for me, Turnitin has a mediating effect, it's about creating almost a kind of barrier between me and my students because it's like okay, you submit to this piece of technology and then there's an expectation that I become an IT expert. [P04]

On contrary, in the more advanced conceptions (C, D) the impact of the medium is seen along the lines of enabling the enhancement of learning (Category $\mathrm{C}$ ) or enhancing learning and extending to pursuing collective objectives (Category D).

So I'm more interested in student skills moving beyond the written word and finding more ways of connecting ideas. [...] I thought that using a medium also has a way of encouraging students to work together on assessment. So although in this particular module students work individually, they do a lot of collaboration online to develop their digital story. [P12]

Across all categories, academics foregrounded the intended purpose of the e-assessment platform and made limited references to specific functionalities of the tools available to them. Quite often a particular intended formative or summative use was seen to be served by different platforms, without necessarily paying attention to what is endorsed by their teaching teams, their department or their institution.

The purpose, level and quality of collaboration

In Category A, the purpose of collaboration is to support the administrative processes, the level of collaboration is typically low and is initiated by the teacher or the e-assessment systems. By contrast, in the next three categories, the level of collaboration is high and follows multiple directions between the various e-assessment partners. Equally, the quality of collaboration is seen as relational; it seeks to establish and nurture relationships between all those involved. However, it is the purpose that varies; the intention of collaboration is to promote engagement in Category B, support student learning and the development of ideas/skills in Category $\mathrm{C}$ and, finally, collaboration serves collective processes in Category D. This variation in the role of e-assessment collaboration often becomes possible with academics' active choices of particular e-assessment platforms and the designs embedded within them.

The relationship to teaching and learning 
Variation is observed across four categories of description with regard to how e-assessment is seen in relation to learning and, to a lesser extent, teaching. In Category A, e-assessment and learning/teaching are perceived in isolation to each other. Academics' accounts often describe e-assessment as an administrative function that relates to university procedures and workload management. In Category B, the focus shifts away from this understanding of the phenomenon to centre on students, in particular how they are involved in communication channels, how their progress is monitored and how they become aware of the teacher's presence. However, eassessment platforms are still not seen as internally constituted in teaching and learning. Such an understanding only becomes apparent in Category C. Here e-assessment is understood as no different to any other assessment format. The main criterion of success is the extent to which e-assessment helps to achieve the prescribed learning outcomes or, in more broad terms, enhance student learning. Finally, in Category D, the relationship remains internal yet the focus extends beyond learning to examine the success of e-assessment in terms of personal and community development. As one academic described it: 'It's about having some kinds of milestones in their learnings. It helps you more with the formative, and it's not about them just doing something at the end. It's more developmental and it builds a shared community as well' [P12].

The study set out to explore variation in the ways academics conceptualise e-assessment and identified four qualitatively different ways of experiencing this phenomenon within a formal learning, tertiary context. The outcome space (Table 4) depicts the structure of these conceptions: a composite of what is e-assessment and the meaning attached to it (the 'how' of the conception). It also represents the hierarchical nature of these conceptions from less to more advanced ways of experiencing e-assessment. Within the first two conceptions, the technological medium appears to be at the fore of the focus of awareness of teachers and is viewed as a means of managing and streamlining the assessment process, thereby enhancing communication and engagement; therefore, the medium is seen as achieving something external to learning and, to a lesser extent, teaching. The medium is understood as enhancing assessment in terms of fairness, consistency, storage, manageability and quality assurance purposes (Category A) or clarity, seamlessness and timeliness of communication and feedback (Category B). Teachers' accounts of e-assessment consistent with the next two conceptions described it as internally constituted to teaching and learning: 'If you're asking me what are the advantages of e-assessment or the disadvantages, [...] I think you can make assessment exciting, more exciting, and you can make it so much part of the learning that it is almost inseparable' [P10]. The epicentre of meaning attached to the activity of e-assessment is located in learning enhancement: this is predominantly student learning but elements of teacher's learning and development were also revealed.

Table 4: Outcome space: referential and structural aspects of academics' conceptions of eassessment

Referential aspects (the 'what' of the conception)

Structural aspects (the 'how' of the conception)

Technology perspective Learning perspective Collective perspective

\footnotetext{
A: Managing and streamlining the assessment process

$\mathrm{B}$ : Incorporating $\mathrm{A}$ and extending to facilitate dialogue and 


\section{Discussion}

The study, therefore, broadly replicates the distinction reported by Watkins, Dahlin and Ekholm (2005) regarding the internal/external relationship between summative assessment and teaching. Participants' descriptions in this study, resonate in particular with what has been reported as assessment 'intentionally designed to contribute to students' development' (Watkins, Dahlin, and Ekholm 2005, p. 295). Such an intentional approach in the context of e-assessing student work refers to the active choices of the design of assessment tasks, decisions on how to meet external requirements in a way that is not detrimental to student learning, judgements about the necessity or suitability of e-assessment platforms, a negotiation regarding acceptance or rejection of institutionally-provided platforms and, finally, a substantial element of negotiating these choices with students. The relationship between teaching/learning on the one hand, and assessment on the other has been at the core of rethinking university teaching as exemplified in the rationale for constructive alignment, assessment for learning and the efforts to promote assessment literacy. The study offers evidence that the separation of these two domains continues to exist within newly-formed, technology-rich educational milieus such as online systems facilitating formative and summative assessments.

The results of the current phenomenographic study on academics' conceptions of e-assessment demonstrate substantial variation in their experiences and understanding of the integration of technology to support summative and formative functions and purposes of assessment in university settings. Variation is evident across as well as within the reported categories of description. The breadth of such variation partially derives from the aim of the study to capture all experiences of assessment regardless of their functions and purposes, level of study and technological medium. The emergence of the fourth category of description can be attributed to the adoption of socially-oriented platforms for mostly formative and - to a lesser extent - summative assessments, the pressure for accountability and the need for universities to demonstrate value in their teaching. Relatively strong representation of academics with socially-orientated disciplinary contexts (e.g. Education, Social Work) may have contributed to the same effect. It becomes apparent that e-assessment cannot be understood without explicitly recognizing that the online mediated relationship between the assessed and the assessor is itself formulated by the relationships that each partner has to a wider nexus of relationships inclusive of those which exist entirely in the online domain. This can be the immediate (digital) cohort for the students or departmental/university life for the academic, professional communities, or wider societal structures and online spaces.

The study extends the boundaries of previous phenomenographic and non-phenomenographic studies reporting on conceptions of assessment (e.g. Samuelowitz and Bain 2002) in that the findings reveal the aforementioned socially-oriented/collective approach. It is noteworthy, however, that a similar conception was reported in a rudimentary form by Lameras et al. (2012); this approach is more fully manifested in the current study. Results from phenomenographic studies in a technology-mediated university do not precisely match to the contentprocess continuum of earlier studies detailing face-to-face conceptions. It has been argued that when online technologies are introduced into the learning experience, the structure of conceptions and approaches in relation 
to a given task become more complex since the experiences are mediated by a technological tool (Ellis and Bliuc 2017).

Academics from seventeen distinct disciplines and fields of study shared their experiences of assessing student work with web-enabled platforms. Their accounts, however, were limited to the context of one particular institution. It is also noteworthy that this institution was at an advanced stage of transitioning to e-assessment practices with fresh institutional memories of 'red-pen-and-paper' feedback and assessment practices. Further research is deemed necessary to explore qualitative differences in the experiences of academics in fully online assessment contexts. A robust theoretical classification of e-assessment media and designs will enable assessors to align their media choices with the purpose and intent of their formative and summative assessment tasks. In this context, the potential of technologies to accomplish advanced formative purposes that can eliminate summative functions (Cope and Kalantzis 2015) should be further explored. Elements of conceptions B, C, D can be conducive to promoting assessment for learning in the online context and allow for the enactment of notions of 'teaching presence', 'learning enhancement', and facilitating personal and collective development. The latter in particular resonates with remarks that 'assessment for learning must provide guidance [...] that encourages the learner to direct energy towards growth, rather than well-being' (Wiliam 2011, p. 13). How these conceptions are enacted, however, relies on a rather complex nexus of technology, pedagogical knowledge - and (lack of) willingness to apply it - and institutional support. Most importantly, assessment for learning foregrounds that assessment is essential to adjust teaching, promoting therefore an integrative view of both teaching and assessment. The dimension of variation reported in this study, demonstrated conceptions that see assessment and teaching/learning as integral as well as external and unrelated. How this integration takes place within formal learning environments and how 'external' conceptions are modified can form two priority areas that invite technologies innovation as well as nuanced approaches to teachers' pedagogical development.

Such integration should also take account of the specific requirements of how knowledge and skills are assessed across academic fields and disciplines. Disciplinary variation emerged in conceptions of e-assessment with participants from 'hard' disciplines perceiving assessment as a mechanism of testing and validating acquisition of knowledge, whereas their colleagues from social sciences/humanities often focused on transformative notions of assessment which prioritise student involvement, negotiation, co-authoring and participation. Further research is needed in this area, in particular how assessment formats and platforms mediate the assessment of disciplinary knowledge and skills.

The current study contributes to the understanding of the experiences of academics in e-assessment and highlighted aspects of how academics may use the same functionality (e.g. plagiarism detection software) to serve different purposes (e.g. formative feedback or penalizing students). The reported categories represented qualitatively different ways of relating to the educational contexts within which they are expected to formatively improve and summatively assign a value to student work using web-enabled mechanisms. Such categories, ultimately, represent an increasing level of agency both for the assessing academic and the assessed student.

\section{References}

Åkerlind, G. S. (2012). Variation and commonality in phenomenographic research methods. Higher Education 
Research \& Development, 31(1), 115-127.

Åkerlind, G. S., \& Kayrooz, C. (2003). Understanding academic freedom: The views of social scientists. Higher Education Research \& Development, 22(3), 327-344.

Argyris, C., \& Schön, D. (1974). Theory in practice: Increasing professional effectiveness. San Francisco, CA: Jossey-Bass.

Becher, T., \& Trowler, P. (2001). Academic Tribes and Territories: intellectual enquiry and the cultures of disciplines. Buckingham: Open University Press/SRHE.

Biggs, J.B., \& Tang, C. (2007). Teaching for quality learning at university: What the student does. Buckingham: Open University Press/SRHE.

Black, P., Harrison, C., Lee, C., Marshall, B., \& Wiliam, D. (2007). Assessment for learning. New York: Open University Press.

Boud, D., \& Molloy, E. (2013). Rethinking models of feedback for learning: the challenge of design. Assessment \& Evaluation in Higher Education, 38(6), 698-712.

Brown, R., \& Carasso, H. (2013). Everything for sale?: the marketisation of UK higher education. London: Routledge.

Cope, B., \& Kalantzis, M. (2015). Sources of Evidence-of-Learning: Learning and assessment in the era of big data. Open Review of Educational Research, 2(1), 194-217.

Ellis, R. A., \& Bliuc, A. M. (2017). Exploring new elements of the student approaches to learning framework: The role of online learning technologies in student learning. Active Learning in Higher Education. First published online, 7 August. https://doi.org/10.1177/1469787417721384.

Ellis, R., Hughes, J., Weyers, M., \& Riding, P. (2009). University teacher approaches to design and teaching and concepts of learning technologies. Teaching and Teacher Education, 25, 109-117.

Ellis, R., Steed, A., \& Applebee, A. (2006). Teacher conceptions of blended learning, blended teaching and associations with approaches to design. Australasian Journal of Educational Technology, 22(3), 312335.

Entwistle, N. (2000). Promoting deep learning through teaching and assessment: conceptual frameworks and educational contexts. Paper presented at the TLRP Conference, Leicester, November.

Gibbs, G. \& Simpson, C. (2004). Conditions under which assessment supports students learning. Learning and Teaching in Higher Education.1, 3-31.

Gikandi, J. W., Morrow, D., \& Davis, N. E. (2011). Online formative assessment in higher education: A review of the literature. Computers \& Education, 57(4), 2333-2351.

Gipps, C. (1999). Socio-cultural aspects of assessment. Review of Research in Education, 24(1), 355-392.

González, C. (2009). Conceptions of, and approaches to, teaching online: a study of lecturers teaching postgraduate distance courses. Higher Education, 57, 299-314.

González, C. (2010). What do university teachers think eLearning is good for in their teaching? Studies in Higher Education, 35(1), 61-78.

Gurwitsch, A. (1964). The field of consciousness. Pittsburgh, PA: Duquesne University Press.

Hattie, J., \& Timperley, H. (2007). The power of feedback. Review of Educational Research, 77(1), 81-112.

Higher Education Funding Council for England (2017). National Student Survey results. Survey. Accessed 
December 10. http://www.hefce.ac.uk/lt/nss/results/2017/

Kember, D. (1997). A reconceptualisation of the research into university academics' conceptions of teaching. Learning and Instruction, 7(3), 255-275.

Kember, D. (1998). Teaching beliefs and their impact on students' approach to learning. In B. Dart \& G.

Boulton-Lewis (Eds.), Teaching and Learning in Higher Education, (pp. 1-25). Melbourne: Australian Council for Educational Research.

Kvale, S. (1996). Interviews: An introduction to qualitative research interviewing, Thousand Oaks, CA: Sage.

Lameras, P., Levy, P., Paraskakis, I., \& Webber, S. (2012). Blended university teaching using virtual learning environments: conceptions and approaches. Instructional Science, 40(1), 141-157.

Marton, F. (1986). Phenomenography — a research approach to investigating different understandings of reality. Journal of thought, 21:28-49.

Marton, F. \& Booth, S. (1997). Learning and Awareness. Mahwah, NJ: Lawrence Erlbaum Associates.

Nicol, D. J., \& Macfarlane-Dick, D. (2006). Formative assessment and self-regulated learning: A model and seven principles of good feedback practice. Studies in Higher Education, 31(2), 199-218.

Pachler, N., Daly, C., Mor, Y. \& Mellar, H. (2010). Formative e-assessment: Practitioner cases. Computers \& Education, 54(3), 715-721.

Postareff, L., Virtanen, V., Katajavuori, N., \& Lindblom-Ylänne, S. (2012). Academics' conceptions of assessment and their assessment practices. Studies in Educational Evaluation, 38(3), 84-92.

Prosser, M., Trigwell, K. \& Taylor, P. (1994). A Phenomenographic Study of Academics' Conceptions of Science Learning and Teaching. Learning and Instruction. 4(3), 217-232.

Ramaprasad, A. (1983). On the definition of feedback. Behavioral Science, 28(1), 4-13.

Ramsden, P. (1994). Learning to Teach in Higher Education. London: Routledge.

Renström, L. (1988). Conceptions of matter: A phenomenographic approach. In Goteborg Studies in Educational Sciences, Vol. 69, Goteborg: Acta Universitatis Gothoburgensis.

Samuelowicz, K. \& Bain, J.D. (2002). Identifying academics' orientations to assessment practice, Higher Education, 43, 173-201.

Snyder, B.R. (1971). The hidden curriculum. New York: Alfred A. Knopf.

Thomson, K., \& Falchikov, N. (1998). "Full on Until the Sun Comes Out": the effects of assessment on student approaches to studying. Assessment \& Evaluation in Higher Education, 23(4), 379-390.

Tremblay, K., Lalancette, D., \& Roseveare, D. (2012). Assessment of higher education learning outcomes. Assessment of Higher Education Learning Outcomes (AHELO) Feasibility study report, 1. Organisation for Economic Co-operation and Development (OECD).

Vergés Bausili, A. (2017). From piloting e-submission to electronic management of assessment (EMA): Mapping grading journeys. British Journal of Educational Technology. First published online 22 February. https://doi:10.1111/bjet.12547.

Watkins, D., Dahlin, B., \& Ekholm, M. (2005). Awareness of the backwash effect of assessment: A phenomenographic study of the views of Hong Kong and Swedish lecturers. Instructional Science, 33(4), 283-309.

Wiliam, D. (2011). What is assessment for learning? Studies in Educational Evaluation, 37(1), 3-14.

Wiliam, D., \& Black, P. (1996). Meanings and Consequences: A Basis for Distinguishing Formative and 
Summative Functions of Assessment? British Educational Research Journal, 22(5), 537-548. 